\title{
Salicylaldoximes and anthranylaldoximes as alternatives to phenol- based estrogen receptor ligands
}

\author{
Filippo Minutolo, ${ }^{a}$ Simone Bertini, ${ }^{a}$ Adriano Martinelli, ${ }^{a}$ Gabriella Ortore, ${ }^{a}$ Giorgio

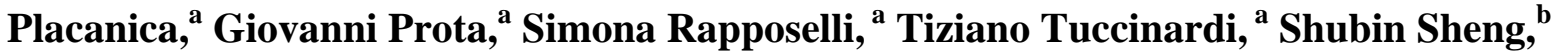 \\ Kathryn E. Carlson, ${ }^{c}$ Benita S. Katzenellenbogen, ${ }^{b}$ John A. Katzenellenbogen, ${ }^{c}$ Marco \\ Macchia $^{a} *$ \\ ${ }^{a}$ Dipartimento di Scienze Farmaceutiche, Università di Pisa, Via Bonanno 6, 56126 Pisa, Italy \\ ${ }^{b}$ Department of Molecular and Integrative Physiology University of Illinois, 407 S. Goodwin \\ Avenue, Urbana, IL 61801, USA \\ ${ }^{c}$ Department of Chemistry, University of Illinois, 600 S. Mathews Avenue, Urbana, IL 61801, \\ USA \\ E-mail: mmacchia@farm.unipi.it
}

\begin{abstract}
Estrogens play a crucial role in the development and function of female reproductive tissues. They have positive effects on the maintenance of bone mineral density, on the liver, and on the cardiovascular and central nervous systems.

Selective Estrogen Receptor Modulators (SERMs) are particularly attractive as therapeutic agents because they are able to block estrogen action at those sites where stimulation would be undesirable, such as the breast and uterus, but at the same time stimulate estrogen actions in other tissues where they are desired, such as the bone and liver.

Most synthetic estrogen receptor ligands possess a phenolic ring, mimicking the phenolic "Aring" of the natural ligand estradiol.

In an attempt to increase the structural diversity of estrogen receptor (ER) ligands, we designed and synthesized molecules containing unprecedented replacements of the prototypical phenolic "A-ring" of estrogens with an oxime and a hydroxy- (salicylaldoximes) or aminomoieties (anthranylaldoximes), forming intramolecularly H-bonded pseudocycles. These new classes of compounds showed interesting ER binding properties on both receptor subtypes (ER $\alpha$ and ER $\beta$ ). These results proved that the six-membered ring formed by an intramolecular hydrogen bond, and containing an exocyclic oxime $\mathrm{OH}$, is an effective stereoelectronic replacement of the phenolic ring of typical ER ligands.
\end{abstract}

Keywords: Estrogen, ligands, nuclear receptors, binding, oximes 


\section{Introduction}

Many important physiological processes may be regulated by an appropriate modulation of the estrogen receptors (ER). For example, an ER agonist action has positive effects in estrogen deficiencies (hormone replacement therapy), in the maintenance of bone mineral density (osteoporosis), in lowering blood lipid levels (atherosclerosis and other cardiovascular diseases), and in the central nervous system functions. ${ }^{1-3}$ On the other hand, an estrogen agonist action on uterus and breast may increase the risk of cancer insurgence in those tissues. ${ }^{4,5}$ For these reasons, molecules able to antagonize the tumor-promoting effect of endogenous estrogens and, at the same time, to promote estrogen-like effects in tissues where they are desired, are named "Selective Estrogen Receptor Modulators" or "SERMs" (Figure 1). ${ }^{6-9}$

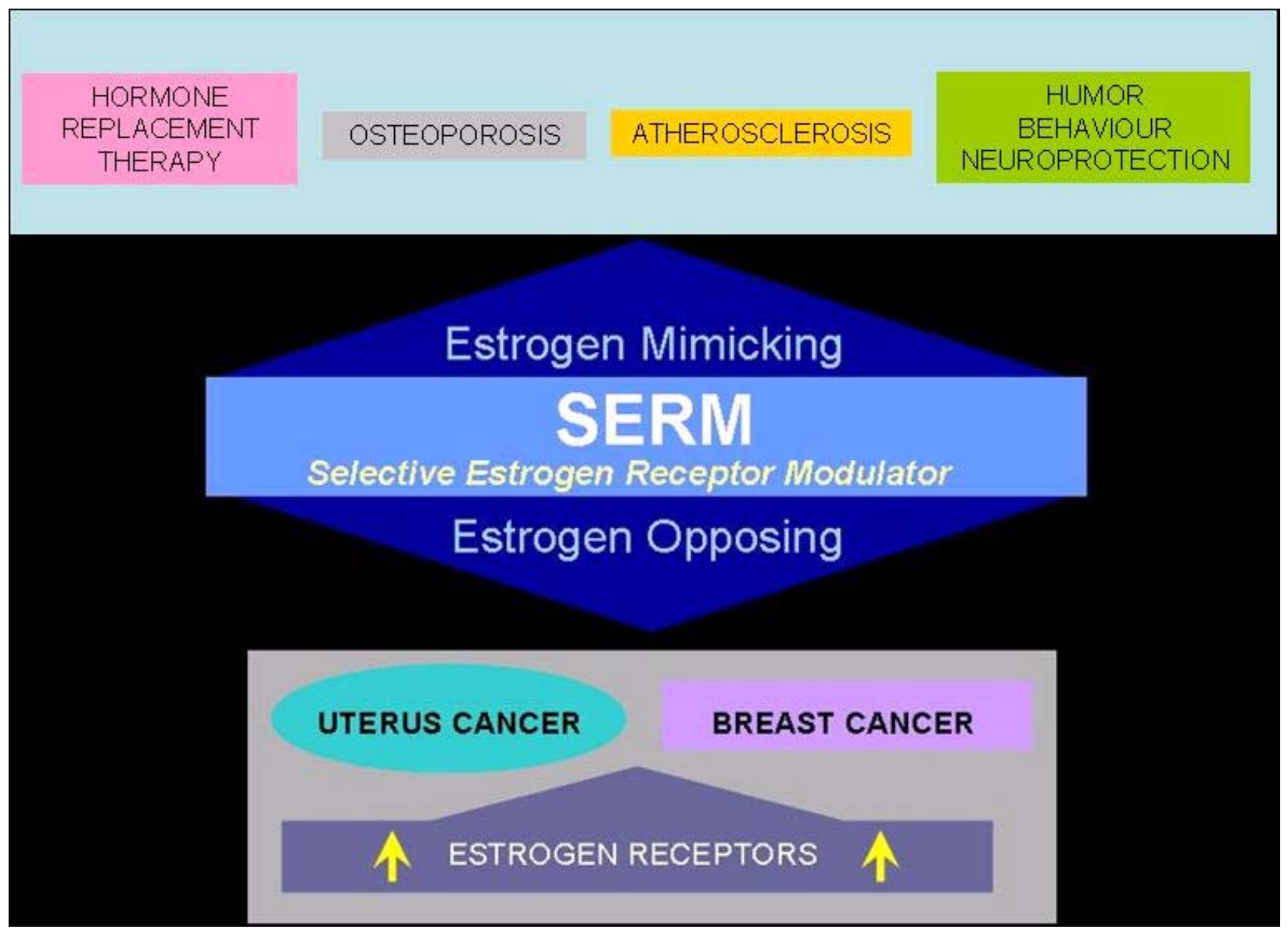

Figure 1

Nowadays, two subtypes of the ER have been identified, ER $\alpha$ and ER $\beta,{ }^{10}$ and they act as ligand-inducible nuclear transcription factors (Figure 2). ${ }^{11}$ Their action is always influenced by the presence of coregulatory proteins (coactivators, corepressors, etc.) within the cells of different tissues, which eventually determine the final physiological effects. ${ }^{12}$ 


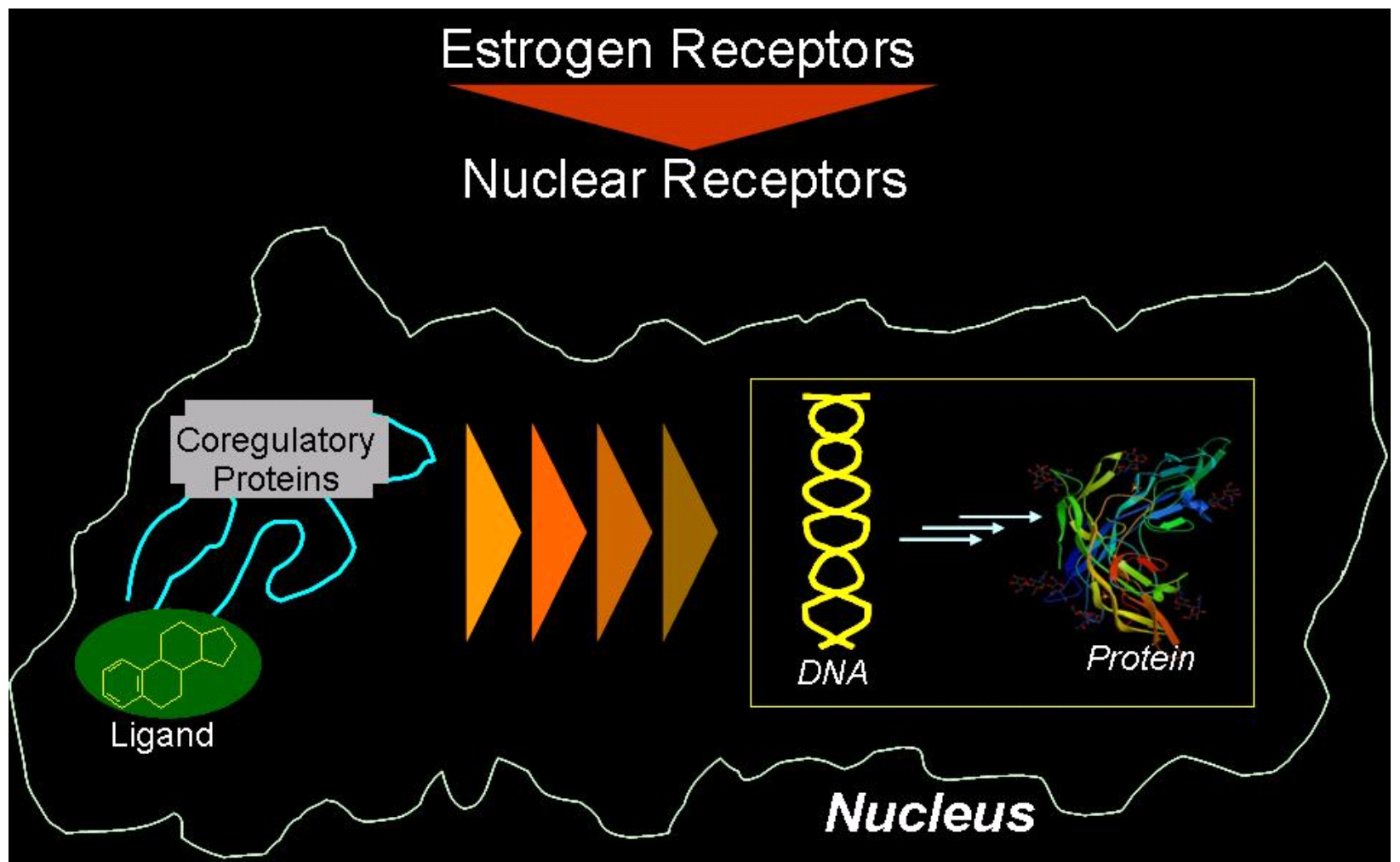

Figure 2

\section{Results and Discussion}

In spite of a remarkable variety of molecular structures found in the many classes of nonsteroidal ER ligands known so far, a striking chemical feature common to nearly all synthetic ER ligands possessing a good binding affinity is the presence of a phenolic ring (A, pharmacophore

model, Figure 3 ) that seems to mimic the steroid "A-ring" present in natural estrogens. ${ }^{13}$ This phenolic group is thought to be responsible for much of the binding energy between ligand and receptor, because of its participation in a hydrogen-bond network which includes two specific residues of the ER ligand binding domain, Glu353(305) and Arg394(346) of ER $\alpha(E R \beta) .{ }^{14,15}$

In an investigation of new molecular entities that might bind to the ER with improved SERM properties, and thereby increase the structural diversity of estrogen ligands, we have developed 3,4-diaryl-substituted salicylaldoxime and anthranylaldoxime ligands (Figure 3). ${ }^{16-19}$ These classes of compounds possess an unprecedented bioisosteric replacement of the phenolic A group with hydroxy-substituted 6-membered pseudo-rings (A'), formed by an intramolecular hydrogen bond. This ring (A') presents several features that indicate its similarity with the phenolic A-ring: (i) both rings have approximately same size and same planar $\pi$-conjugated (at least partially, in the case of the salicylaldoximes) hexagonal geometry; (ii) the $\mathrm{OH}$ of the oxime group is attached to an $\mathrm{sp}^{2}$ hybridized atom (nitrogen) that is intramolecularly hydrogen-bonded 
to the ortho phenol, and has an estimated $\mathrm{pKa}$ value around 10, within the $\mathrm{pKa}$ range of typical phenolic $\mathrm{OH}$ groups; and (iii) the position of the oxime $\mathrm{OH}$ group corresponds to the position 3 of the phenolic A ring, i.e., the position actually occupied by an $\mathrm{OH}$ in classical ER ligands (Figure 3).

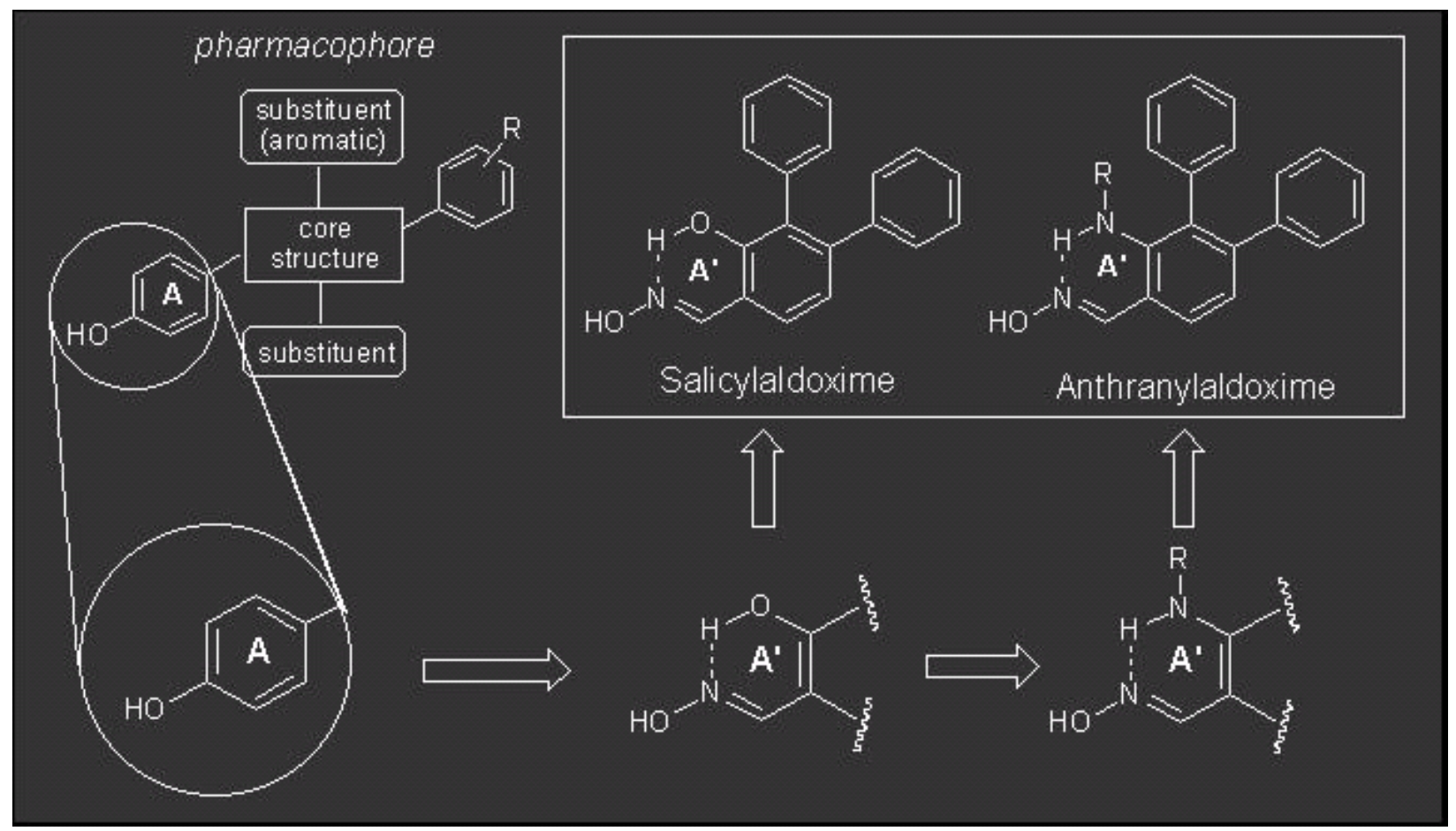

Figure 3

The binding affinities of these new compounds were determined in radiometric competitive binding assays with purified full-length human ER $\alpha$ and ER $\beta$. The data reported in Figure 4 are expressed as the relative binding affinity (RBA) values relative to estradiol, which is set at $100 \% .^{20,21}$ The affinity of estradiol for the two receptors is high: $K_{d}(E R \alpha) 0.2 n M ; K_{d}(E R \beta) 0.5$ $\mathrm{nM}$.

The diphenylsubstituted salicylaldoxime already proved to have interesting binding properties for both estrogen receptor subtypes (RBA $=1.1 \%$ with $\mathrm{ER} \alpha$ and $1.7 \%$ with ER $\beta$ ), thus confirming the good hypothesized mimicry of the pseudocycle A' for the phenol group of typical ER ligands. We then replaced the oxygen atom of the pseudocycle with an aniline-type unsubstituted nitrogen, and the resulting $\mathrm{N}$-H-anthranylaldoxime showed an improved binding affinity on both $\operatorname{ER} \alpha$ and $\operatorname{ER} \beta$ (2.2\% and $2.8 \%$, respectively). At this point we wanted to investigate the effect of the introduction of small alkyl groups on the aniline-type nitrogen atom. The $N$-methyl analogue showed a further improvement, especially on ER $\beta$, in the binding affinities $(\mathrm{RBA}=3.7 \%$ with $\mathrm{ER} \alpha$ and $5.2 \%$ with $\mathrm{ER} \beta)$. Surprisingly, the binding affinities of the immediately higher $\mathrm{N}$-ethylated homologue were much lower than the $\mathrm{N}$-Me derivative; in fact 
its binding affinity on ER $\alpha$ dropped by about 10 fold and more than 100 fold on ER $\beta$, compared to the $N$-Me analogue.

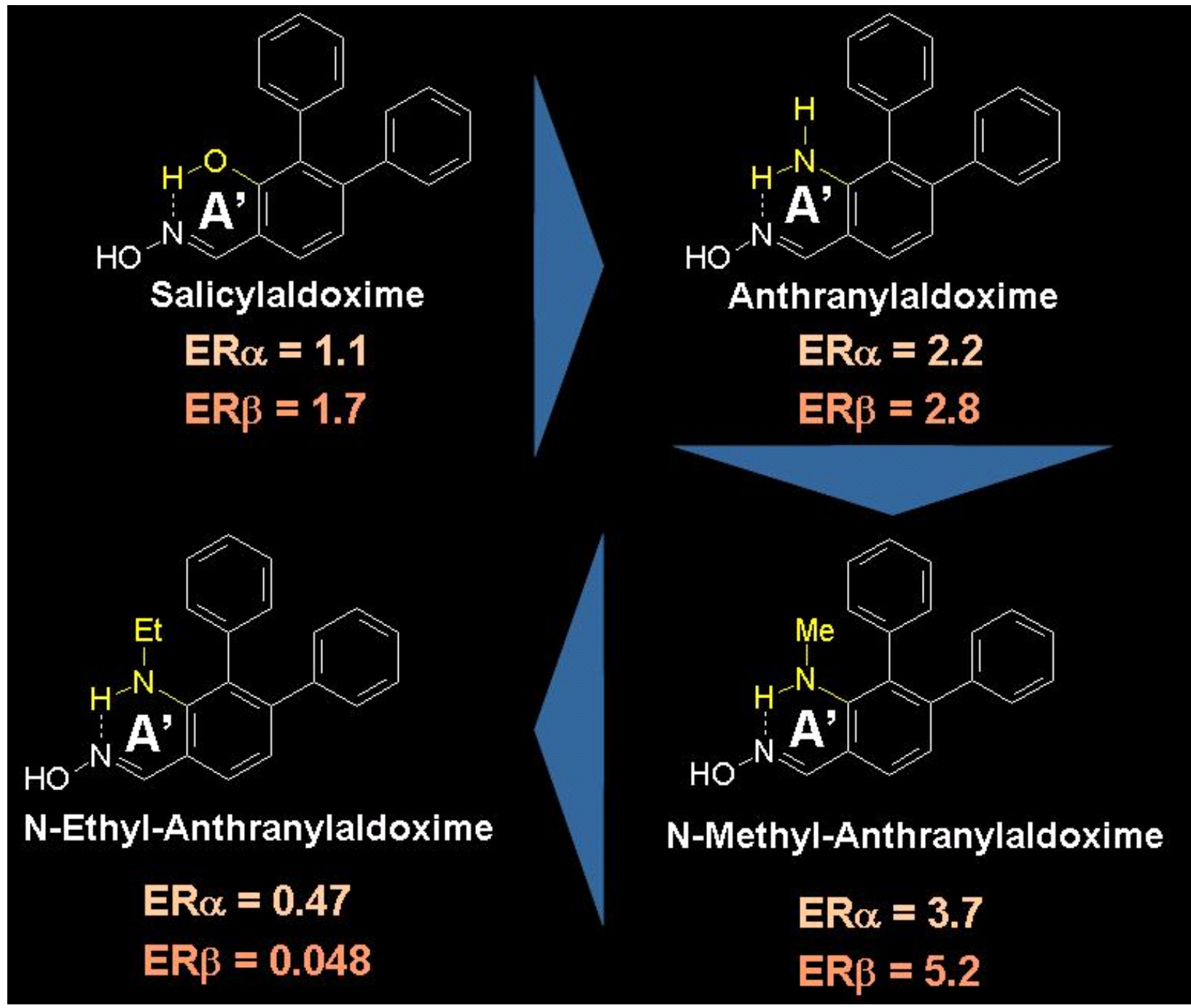

Figure 4

In order to understand the possible binding modes of these compounds and to explain the drop in binding affinity of the $\mathrm{N}$-Et-anthranylaldoxime, we performed molecular docking experiments on $\mathrm{ER} \alpha$ (Figure 5).

In these experiments we found that the pseudo-ring $\mathrm{A}^{\prime}$ of $\mathrm{N}-\mathrm{H}$ and $\mathrm{N}$-Me-anthranylaldoxime could be positioned where estradiol had its phenolic A-ring, allowing for an efficient participation of the oxime $\mathrm{OH}$ in the same hydrogen-bonding network with Arg394 and Glu353 in which estradiol is involved. The aromatic central cores of these compounds (indicated as B) perfectly replaces the B-ring of estradiol, and the two phenyl substituents protrude towards the relatively hydrophobic empty spaces in the receptor ligand binding pocket. 
It should be noticed that $N$-Me-anthranylaldoxime places its $N$-methyl group in a small hydrophobic pocket defined by Leu346, Leu349, and Ala350 (Figure 5, left panel). Salicylaldoxime (not shown) displayed a similar spatial arrangement within the ER $\alpha$ binding domain.

By contrast, the higher homologue with the $N$-ethyl substituent was not able to assume a similar binding mode within the ligand binding pocket as defined in the ER $\alpha$-estradiol X-ray structure, when the pocket was rigidly fixed during the modeling. In fact, there is a steric clash between the $N$-Et substituent and the residue Leu349 (Figure 5, right panel). These repulsive van der Waals interactions that take place in the binding process of $N$-Et-anthranylaldoxime with the receptor might explain the much lower binding affinity values found for this compound.

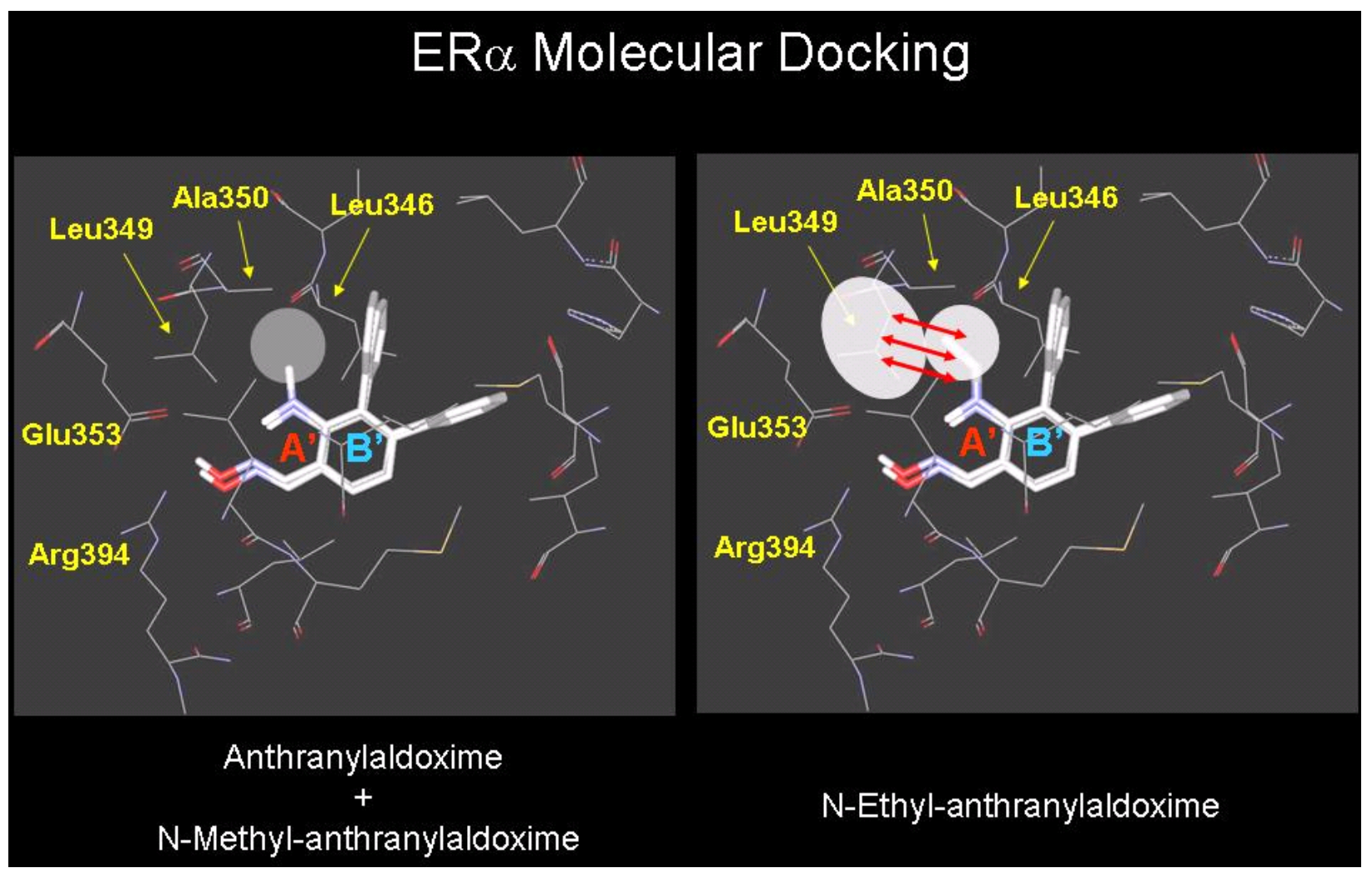

\section{Figure 5}

A further examination of different classes of reported synthetic ER ligands shows that the introduction in these molecules of additional peripheral phenolic hydroxy-groups causes an improvement of their binding properties. This fact was explained by the intervention of additional hydrogen-bonds or other types of hydrophilic interactions between these new phenolic groups and other polar functions on residues present nearby in the ligand binding pocket of the receptor.

Based on these considerations, we initially started to design and synthesize salicylaldoximes possessing polar groups in either one of the 3-and 4-aryl substituents, or in both of them. The 
most promising compounds, in terms of binding affinity properties, turned out to be the ones having a single $p$-hydroxy group on the distal (4-position) or proximal (3-position) phenyl substituents (Figure 6).

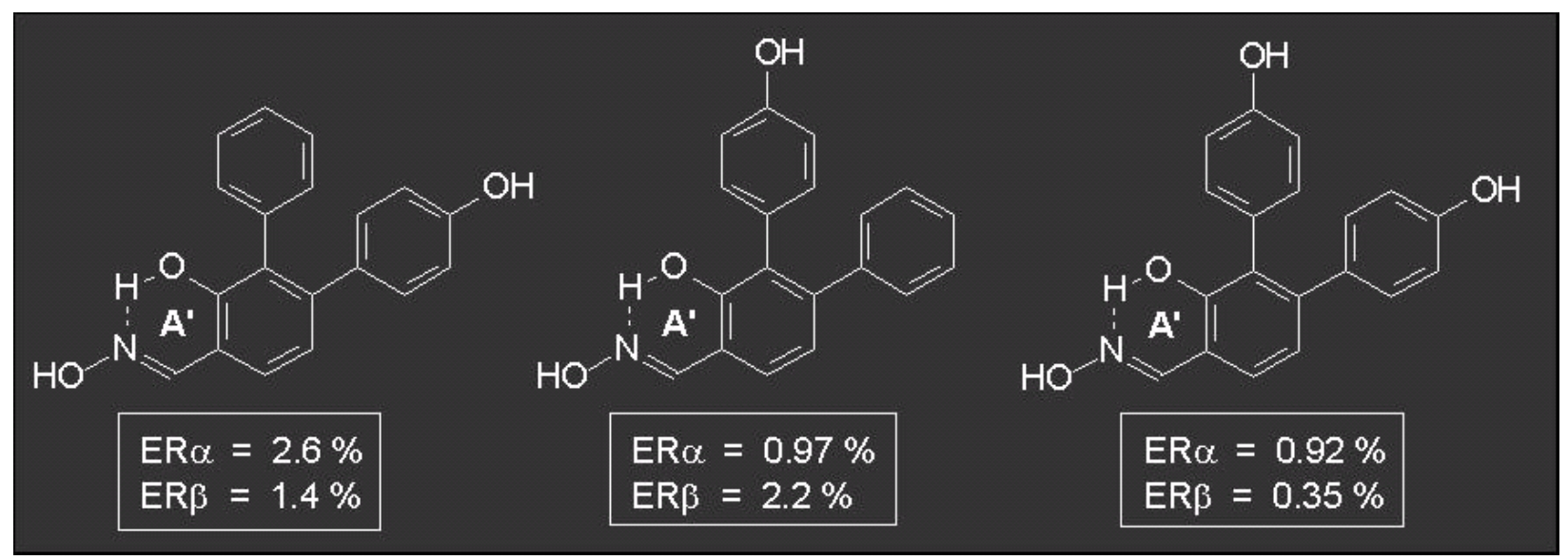

\section{Figure 6}

An analysis of the results shows that the compound containing a $p$-hydroxy group only on the $\mathrm{C}(4)$ phenyl substituent (distal), possesses a binding affinity (2.6\%, Figure 6) on ER $\alpha$ that is 2.5 times better than its non-substituted counterpart (1.1\%, Figure 4$)$. This trend is accompanied by a slight decrease on ER $\beta$ (1.4\% vs. 1.7\%). On the other hand, the introduction of a $p$-hydroxy group on the $C(3)$ phenyl substituent (proximal), caused a shift in the $\alpha / \beta$ preference in favor of the $\beta$ subtype $(\beta / \alpha \approx 2)$, due to a slight improvement of the affinity on ER $\beta(2.2 \%)$ with respect to its unsubstituted counterpart $(1.7 \%)$. The compound possessing $p$-hydroxy groups in both phenyl substituents exhibited a decreased binding affinity on both ER subtypes with respect to its unsubstituted precursor, with a more striking reduction on ER $\beta$.

These results show that there are improvements in the RBA due to the introduction of only one hydroxyl substituent, with a certain preference for $\mathrm{ER} \alpha$ when the $p-\mathrm{OH}$ group is placed on the distal phenyl, or for ER $\beta$ when the same group is placed on the proximal phenyl. However, when $p$-hydroxy groups are introduced in both phenyl substituents, the binding affinity values for both receptor subtypes were decreased. This might be due to the fact that ERs, especially ER $\beta$, do not tolerate high levels of polarity.

Evaluations on the effects of peripheral substituents in anthranylaldoximes are currently under investigation.

As for the synthesis of these derivatives, an interesting synthetic strategy was developed for the preparation of hetero-disubstituted salicylaldoximes. The synthetic route included a double Pd-catalyzed cross-coupling reaction on a bromo-chloro-disubstituted aryl precursor (Scheme 1). This approach exploits the different reactivity of aryl-bromides and aryl-chlorides towards the chosen boronic acids under different reaction conditions, Suzuki-type conditions for the bromides $^{22}$ and Fu-type conditions for the chlorides, ${ }^{23}$ and it provides an efficient way to 
selectively introduce different substituents (depending on the boronic acid used) in those positions.

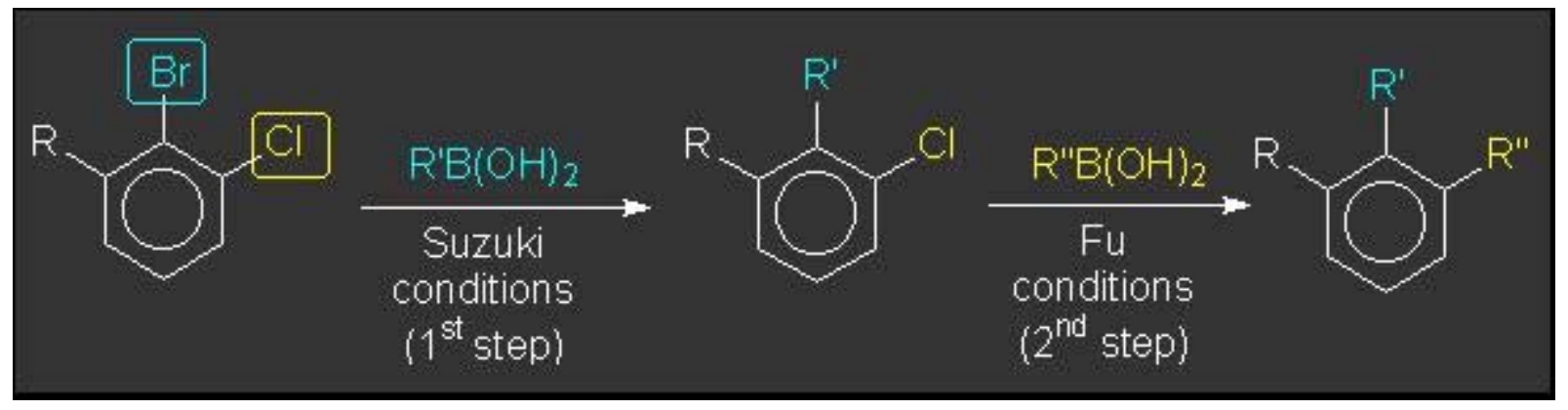

\section{Scheme 1}

As an example, the complete synthesis of salicylaldoxime containing a $p$-hydroxy group on the distal phenyl substituent is shown in Scheme 2. 2-Bromo-3-chloronitrobenzene ${ }^{24}$ was first submitted to a classical Suzuki-type cross-coupling reaction, ${ }^{22}$ using $\mathrm{Pd}\left(\mathrm{Ph}_{3} \mathrm{P}\right)_{4}$ as the catalyst, to introduce the first phenyl group in the place of the bromine atom. This step did not affect the chlorine atom, which was then substituted in the second cross-coupling reaction with $p$ methoxyphenyl boronic acid, using the more reactive catalytic system comprised of $\operatorname{Pd}_{2}(\mathrm{dba})_{3}$ together with tricyclohexylphosphine as the catalyst ligand. ${ }^{23}$ Under these conditions, it was possible to introduce the second aryl substituent in place of the aryl-chloride group efficiently, assembling the required diaryl-benzene core unit of these systems.

The nitro-group was then reduced with hydrazine hydrate in the presence of catalytic amounts of ferric chloride and activated carbon. Diazotization of the amine function, followed by acid hydrolysis of the diazonium group, afforded the corresponding phenolic derivative. Treatment with allyl bromide gave the allyl ether, which was directly submitted to a Claisen rearrangement at $180{ }^{\circ} \mathrm{C}$ in $\mathrm{N}$-methylaniline, affording the corresponding $\mathrm{o}$-allyl-substituted phenol. The allylic terminal double bond was submitted to an alkaline isomerization to give $E / Z$ diastereoisomeric mixtures of the compound possessing an internal aryl-conjugated double bond. The salicylaldehyde derivative was then obtained by oxidative cleavage of the double bond, using sodium periodate in the presence of catalytic amounts of osmium tetroxide. Transformation of the methoxy group into a hydroxyl was achieved by a $\mathrm{BBr}_{3}$ demethylation, and this hydroxyaryl-substituted salicylaldehyde, thus obtained, was then condensed with hydroxylamine hydrochloride in refluxing ethanol to give the final oxime. A similar synthetic scheme was followed for the preparation of the salicylaldoxime containing a $p$-hydroxy group on the proximal phenyl substituent, the only difference being in the inversion of the order of reaction of the two arylboronic acids.

The $(E)$-geometry of the oxime moieties in all the compounds synthesized was assigned based on the chemical shift value of their oxime proton, which is in the $\delta 8.28-8.45$ range. This value is typical for aromatic $(E)$-oximes, whereas the $(Z)$-oximes of the same kind usually have values in the $\delta$ 7.3-7.6 range. The downfield chemical shift found with oximes possessing the $(E)$-configuration is due to the greater shielding of the oxime proton when it is on the same side 
and in a close spatial contact with an electronegative oxygen. ${ }^{25}$ The exclusive formation of oxime diastereoisomers of the $(E)$-configuration may be attributed to the stabilization of these diastereoisomers by the intramolecular hydrogen bond between the phenolic $\mathrm{OH}$ and the adjacent oxime nitrogen atom.

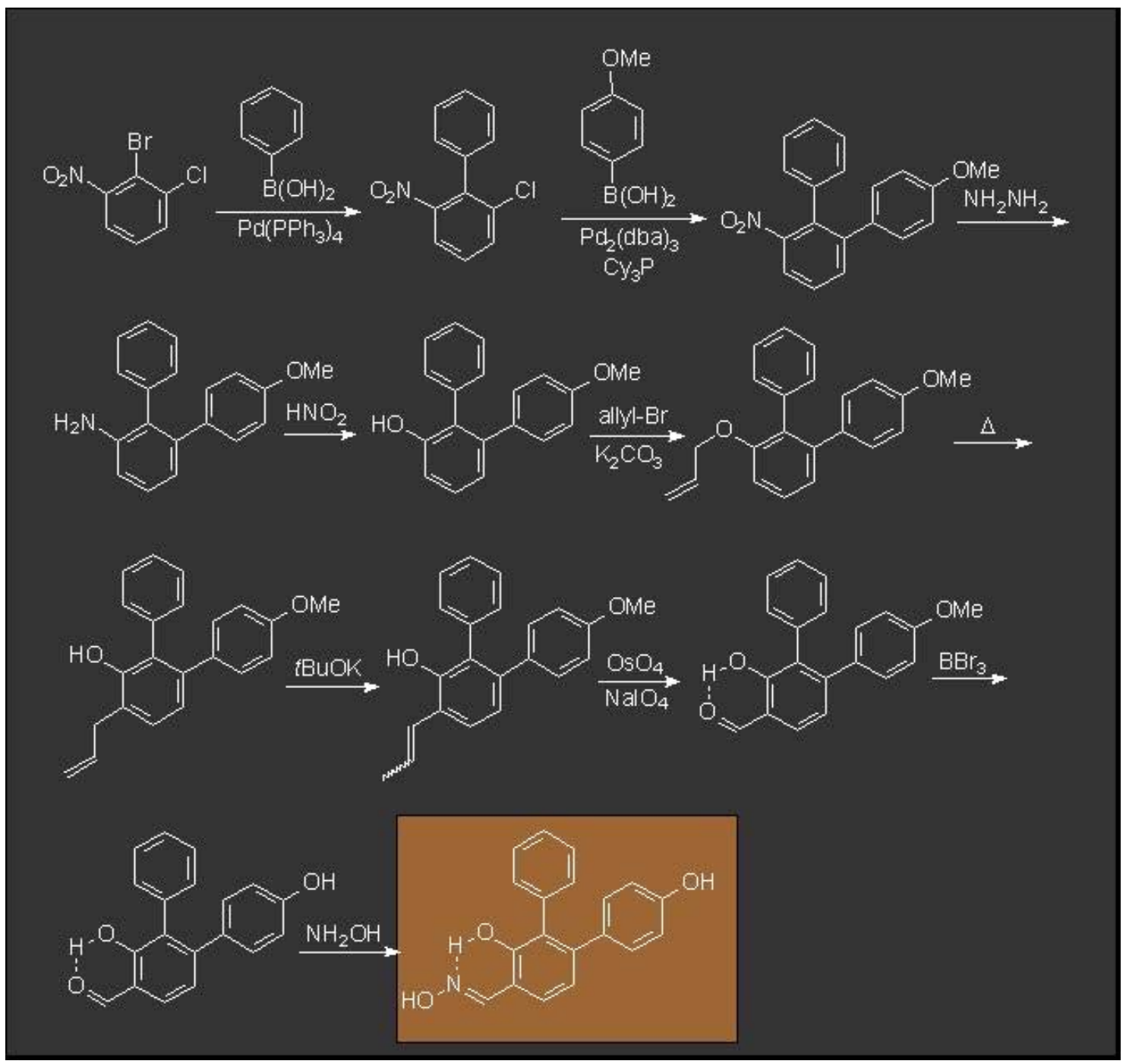

\section{Scheme 2}

The most active compounds were also assayed for transcriptional activity through both receptor subtypes. These cotransfection assays were conducted in human endometrial (HEC-1) cells, using expression plasmids for either full-length human ER $\alpha$ or ER $\beta$ and an estrogenresponsive luciferase reporter gene system. ${ }^{26}$

A representative example of complete dose-response curves is given by $N-H$ anthranylaldoxime shown in Figure 7. In these plots, transcriptional activity (full curve) is normalized relative to that obtained with $1 \mathrm{nM}$ estradiol, which is set at $100 \%$ and antagonist activity (dashed curve) was assayed in the presence of $1 \mathrm{nM}$ estradiol. 

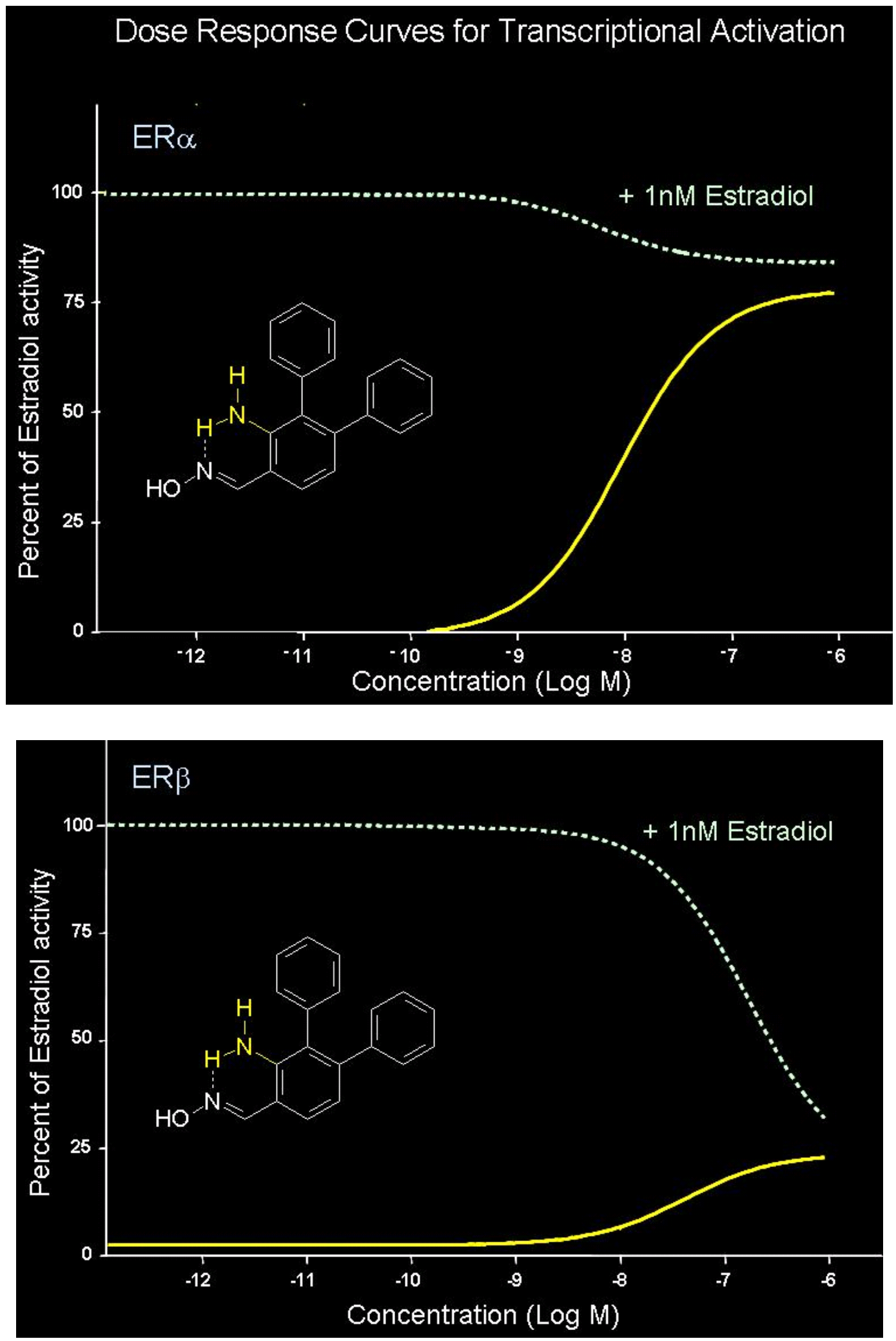

Figure 7 
The full dose-response curves show that $N$-H anthranylaldoxime is a partial agonist on ER $\alpha$ and a partial antagonist on ER $\beta$. The other anthranylaldoxime and salicylaldoxime derivatives show similar transcriptional efficacies, always characterized by a greater level of agonism on $\mathrm{ER} \alpha$ than on ER $\beta$.

\section{Conclusions}

This study was carried out with the aim of finding new SERMs with better biopharmacological profiles. The results obtained with these two classes of salicylaldoximes and anthranylaldoximes show that these compounds are able to efficiently bind both ER $\alpha$ and ER $\beta$. Moreover, the transcriptional activity assays revealed that these compounds possess good modulatory properties on both receptor subtypes and, therefore, may be potentially developed as future efficient SERMs.

\section{References}

1. Cauley, J. A.; Stelley, D. G.; Ensrud, K.; Ettinger, B.; Black, D.; Cummings, S. R. Ann. Intern. Med. 1995, 122, 9.

2. Yaffe, K.; Sawaya, G.; Lieberburg, I.; Grady, D. J. Am. Med. Assoc. 1998, 279, 688.

3. Barrett-Connor, E.; Cox, D. A.; Anderson, P. W. Trends Endocrinol. Metab. 1999, 10, 320.

4. Beresford, S. A.; Weiss, N. S.; Voigt, L. F.; McKnight, B. Lancet 1997, 349, 458.

5. Zumoff, B. Proc. Soc. Exp. Biol. Med. 1998, 217, 30.

6. Cosman, F.; Lindsay, R. Endocr. Rev. 1999, 20, 418.

7. Shang, Y.; Brown, M. Science 2002, 295, 2465.

8. Katzenellenbogen, B. S.; Katzenellebogen, J. K. Science 2002, 295, 2380.

9. Grese, T. A.; Dodge, J. A. Curr. Pharm. Des. 1998, 4, 71.

10. Mosselman, S.; Polman, J.; Dijekema, R. FEBS Lett. 1996, 392, 49.

11. Katzenellenbogen, J. A.; Katzenellenbogen, B. S. Chem. Biol. 1996, 3, 529.

12. Katzenellenbogen, J. A.; O'Malley, B. W.; Katzenellenbogen, B. S. Mol. Endocrinol. 1996, $10,119$.

13. Anstead G. M.; Carlson, K. E.; Katzenellenbogen J. A. Steroids 1997, 62, 268.

14. Brzozowski, A. M.; Pike, A. C. W.; Dauter, Z.; Hubbard, R. E.; Bonn, T.; Engström, O.; Öhman, L.; Greene, G. L.; Gustafsson, J. -Å.; Carlquist, M. Nature 1997, 389, 753.

15. Shiau, A. K.; Barstad, D.; Radek, J. T.; Meyers, M. J.; Nettles, K. W.; Katzenellenbogen, B. S.; Katzenellenbogen, J. A.; Agard, D. A.; Greene, G. L. Nature Struct. Biol. 2002, 9, 359.

16. Minutolo, F.; Bertini, S.; Papi, C.; Carlson, K. E.; Katzenellenbogen, J. A.; Macchia, M. J. Med. Chem. 2001, 44, 4288. 
17. Minutolo, F.; Antonello, M.; Bertini, S.; Placanica, G.; Rapposelli, S.; Carlson, K. E.; Katzenellenbogen, J. A.; Macchia, M. Farmaco 2004, 59, 601.

18. Minutolo, F.; Antonello, M.; Bertini, S.; Rapposelli, S.; Rossello, A.; Sheng, S.; Carlson, K. E.; Katzenellenbogen, J. A.; Macchia, M. Bioorg. Med. Chem. 2003, 11, 1247.

19. Minutolo, F.; Antonello, M.; Bertini, S.; Ortore, G.; Placanica, G.; Rapposelli, S.; Sheng, S.; Carlson, K. E.; Katzenellenbogen, B. S.; Katzenellenbogen, J. A.; Macchia, M. J. Med. Chem. 2003, 46, 4032.

20. Katzenellenbogen, J. A.; Johnson, H. J. Jr.; Myers, H. N. Biochemistry 1973, 12, 4085.

21. Carlson, K. E.; Choi, I.; Gee, A.; Katzenellenbogen, B. S.; Katzenellenbogen, J. A. Biochemistry 1997, 36, 14897.

22. Miyaura, N.; Suzuki A. Chem. Rev. 1995, 95, 2457.

23. Littke, A. F.; Fu, G. C. Angew. Chem. Int. Ed. 1998, 37, 3387.

24. Lamn, B.; Liedholm, B. Acta Chem. Scand. 1967, 21, 2679.

25. Karabatsos, G. J.; Hsi, N. Tetrahedron 1967, 23, 1079.

26. Sun, J.; Meyers, M. J.; Fink, B. E.; Rajendran, R.; Katzenellenbogen, J. A.; Katzenellenbogen, B. S. Endocrinology 1999, 140, 800. 